\title{
Pengaruh Kualitas Pelayanan Kesehatan Terhadap Kepuasan Pasien Penerima Bantuan Iuran Di Puskesmas Pahandut Kota Palangka Raya
}

\author{
Rolly Adinovi ${ }^{1}$, Rinto Alexandro ${ }^{2}$ \\ Universitas Palangka Raya \\ E-mail: rinto.alexandro@fkip.upr.ac.id
}

\begin{abstract}
The purpose of this study is to analyze the significance of the effect of service quality dimensions including reliability, responsiveness, assurance, empathy, tangibles to the level of poor people's health insurance patient satisfaction in Public Health Center of Pahandut Palangkaraya City. Based on the analysis of overall service gap dimensions, the fit between the services provided by health centers in the hope of Palangkaraya Pahandut community insurence patients there is a gap / level of satisfaction (- 10:54), these scores were categorized in groups, although not yet fully meet the expectations of patients community insurence, but service provided is good enough. Based on the results of the regression analysis above we can conclude that all the variables of service quality dimensions (Reliability, Responsiveness, Assurance, Empathy, Tangible) jointly have a significant positive effect on patient satisfaction and Public Health Center of Pahandut Palangka raya City. These results indicate that the alternative hypothesis $(\mathrm{Ha})$ can be accepted and the hypothesis zero (Ho) is rejected. While the major effect is variable Assurance (1052), Reliability (1004), Tangible (1039), Responsiveness (1714), Empathy (1029) on patient satisfaction community insurence. The next is the $R^{2}$ value of (0456) showed that $45.6 \%$ of patient satisfaction variables can be explained by service quality are Reliability, Responsiveness, Assurance, Empathy, and the remaining 54.4\% Tangible while others described the other variables that are not included in this study model. Then, based on gap analysis (a match between expectations of the performance) of each dimension, are as follows, Responsiveness variable (-0.78) score was categorized as moderate. then followed the next variable Tangible variable (-0.88), variable Reliability (-0.57), assurance variable (-0.11), Empathy and the latter variable (-0.11). Although not yet fully provided the service as expected but the district Public Health Center of Pahandut Palangka raya City good enough but should be improved.
\end{abstract}

Key words: Service Quality, Satisfaction, Poor People's Health Insurance Patient

Abstrak

Tujuan penelitian ini adalah untuk Untuk menganalisis Faktor-faktor yang mempengaruhi Tingkat Kualitas Pelayanan Kesehatan yaitu reability, responsiveness, assurance, empaty dan tangible Terhadap Kepuasan Penerima Bantuan Iuran (PBI) di Puskesmas Pahandut Kota Palangka Raya. Berdasarkan analisis gap dimensi pelayanan secara keseluruhan, kesesuaian antara Pelayanan yang diberikan oleh Puskesmas Pahandut Kota Palangka Raya dengan harapan pasien Penerima Bantuan Iuran (PBI) terdapat gap/ tingkat kepuasan sebesar (-10.54), skor ini dikategorikan dalam kelompok sedang, meskipun belum sepenuhnya memenuhi harapan pasien Penerima Bantuan Iuran (PBI), tetapi pelayanan yang diberikan sudah cukup baik. Berdasarkan hasil analisis regresi diatas dapat disimpulkan bahwa semua variabel dari dimensi kualitas pelayanan (Reliability, Responsiveness, Assurance, Empathy, Tangible) secara bersama-sama memiliki pengaruh positif dan signifikan terhadap kepuasan pasien Penerima Bantuan Iuran (PBI) Puskesmas Pahandut Kota Palangka Raya. Hasil tersebut menunjukkan bahwa hipotesis alternatif (Ha) dapat diterima dan hipotesis nihil (Ho) ditolak. Sedangkan besar pengaruhnya adalah variabel Assurance (1.052), Reliability (1.004), Tangible (1.039), Responsiveness (1.714), Empathy (1.029) terhadap kepuasan pasien Penerima Bantuan Iuran (PBI). Selanjutnya nilai adalah $\mathrm{R}^{2}$ sebesar ( 0.456 ) menunjukkan bahwa 45,6\% variabel kepuasan pasien dapat dijelaskan oleh service quality yaitu Reliability, Responsiveness, Assurance, Empathy, dan Tangible sedangkan sisanya 54,4\% lainnya dijelaskan variabel lain yang tidak termasuk dalam model penelitian ini. Berdasarkan hasil analisis gap (kesesuaian antara harapan dengan kinerja) tiap dimensi, adalah sebagai berikut, variabel Responsiveness (-0.78) skor ini dikategorikan sedang. kemudian variabel selanjutnya diikuti variabel Tangible (-0.88), variabel Reliability (-0.57), variabel assurance (-0.11), dan yang terakhir variabel Empathy (-0.11). Meskipun belum sepenuhnya Pelayanan yang diberikan sesuai harapan tetapi pelayanan Puskesmas Pahandut Kota Palangka Raya sudah cukup baik namun harus terus ditingkatkan.

Keywords: Kualitas Pelayanan, Kepuasan Pasien, Penerima Bantuan Iuran

(C) 2021 Jurnal Riset Inspirasi Manajemen dan Kewirausahaan 


\section{PENDAHULUAN}

Pembangunan sosial ekonomi sebagai salah satu pelaksanaan kebijakan pembangunan nasional telah menghasilkan banyak kemajuan, di antaranya telah meningkatkan kesejahteraan rakyat. Kesejahteraan tersebut harus dapat dinikmati secara berkelanjutan, adil, dan merata menjangkau seluruh rakyat. Dinamika pembangunan bangsa Indonesia telah menumbuhkan tantangan berikut tuntutan penanganan berbagai persoalan yang belum terpecahkan. Salah satunya adalah penyelenggaraan jaminan sosial bagi seluruh rakyat, yang diamanatkan dalam Pasal 28H ayat (3) mengenai hak terhadap jaminan sosial dan Pasal 34 ayat (2) Undang-Undang Dasar Negara Republik Indonesia Tahun 1945.

Kesehatan menjadi salah satu tolok ukur kemajuan bangsa disamping tingkat pendidikan dan perekonomian, sebagaimana tercakup dalam Human Development Index (HDI). Alasan tersebut tidak berlebihan jika kesehatan ditempatkan sebagai salah satu kebutuhan terpenting bagi manusia. Tanpa sehat, mausia mustahil dapat melakukan berbagai kegiatan produktif khususnya dalam pembagunan generasi mendatang yang lebih berkualitas. "Kesehatan bukan segala-galanya, namun tanpa kesehatan segala-galanya tidak ada artinya" Health is not everything, but everything without health is nothing - WHO (Dinkes, 2020).

Kepuasan pasien tergantung pada kualitas pelayanan. Pelayanan adalah semua upaya yang dilakukan karyawan untuk memenuhi keinginan pelanggannya dengan jasa yang akan diberikan. Suatu pelayanan dikatakan baik oleh pasien, ditentukan oleh kenyataan apakah jasa yang diberikan bisa memenuhi kebutuhan pasien, dengan menggunakan persepsi pasien tentang pelayanan yang diterima (memuaskan atau mengecewakan, juga termasuk lamanya waktu pelayanan). Kepuasan dimulai dari penerimaan terhadap pasien dari pertama kali datang, sampai pasien meninggalkan puskesmas. Pelayanan dibentuk berdasarkan 5 (lima) prinsip Service Quality yaitu kecepatan, ketepatan, keramahan dan kenyamanan layanan.

Pelayanan kesehatan pada peserta Jaminan Kesehatan Nasional di Kota Palangka Raya tahun 2020 diberikan sesuai petunjuk teknis dari Kementerian Kesehatan RI dengan pemberi pelayanan kesehatan dari Puskesmas dan rumah sakit serta pihak BPJS sebagai Badan Penyelenggara Jaminan Sosial. Masyarakat miskin (maskin) yang sebelumnya ditanggung oleh Jamkesmas dengan aturan baru tersebut kapitasi masyarakat miskin dibiayai oleh pemerintah daerah dengan kategori PBI atau Penerima Bantuan Iuran.

Puskesmas Pahandut Kota Palangka Raya adalah salah satu dari 11 (sebelas) puskesmas sebagai ujung tombak Pemerintah Daerah Kota Palangka Raya dalam menyediakan jasa pelayanan kesehatan primer kepada masyarakat. Pusat Kesehatan Masyarakat (Puskesmas) Pahandut Kota Palangka Raya menjadi unggulan dalam bidang pelayanan kesehatan tingkat dasar di Kota Palangka Raya, hal ini dapat dilihat dari jumlah kunjungan pasien terutama kunjungan pasien Penerima Bantuan Iuran (PBI) yang lebih banyak dibandingkan dengan puskesmas-puskesmas lainnya yang berada diwilayah kerja Dinas Kesehatan Kota Palangka Raya.

Tabel 1. Gambaran Jumlah Kunjungan

Pasien Penerima Bantuan Iuran (PBI) di Kota Palangka Raya Tahun 2015 sampai dengan Tahun 2019.

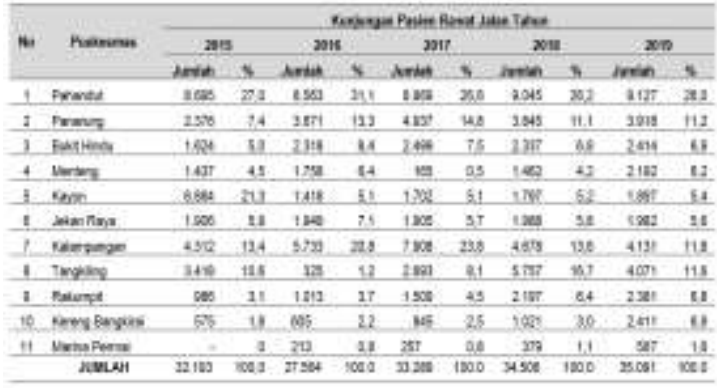

Sumber: Laporan Kepesertaan dan Pelayanan Kesehatan Peserta Penerima Bantuan Iuran (PBI) Tingkat Kota Palangka Raya, Dinas Kesehatan Kota Palangka Raya

Tingginya jumlah kunjungan pasien Penerima Bantuan Iuran (PBI) yang beobat ke Puskesmas Pahandut Kota Palangka Raya disebabkan beberapa faktor diantaranya yaitu akses transportasi menuju ke tempat pelayanan kesehatan Puskesmas Pahandut sangat mudah, karena dekat dengan terminal angkutan dalam kota. Disamping itu Puskesmas Pahandut Kota Palangka Raya pernah mendapatkan Piala Citra Pelayan Prima, dari Presiden RI Susilo Bambang Yudhoyono pada tahun 2006. Piala Citra Pelayanan Prima diberikan kepada unit pelayanan publik yang meraih nilai predikat terbaik dengan aspek penilaian diantaranya kepastian tentang biaya, waktu pelayanan, kepastian tentang prosedur pelayanan serta sarana prasarana dan manajemen organisasi.

Mutu pelayanan puskesmas dinilai baik, apabila pelayanan puskesmas yang diselenggarakan dapat menimbulkan rasa puas pada diri setiap pasien peserta BPJS Penerima Bantuan Iuran (PBI) yang menjadi sasaran puskesmas. Hasil penelitian menunjukkan bahwa variabel yang mempunyai pengaruh yang signifikan terhadap kepuasan pasien 
adalah variabel informasi dan hubungan antar manusia, variabel yang tidak memiliki pengaruh dengan tingkat kepuasan pasien adalah variabel ketepatan waktu dan lingkungan. (Siregar, Rismahani, 2018)

Untuk itu, langkah awal yang harus dilakukan adalah mengetahui dimensi kualitas apa saja yang mempengaruhi kepuasan pasien, utamanya pasien Penerima Bantuan Iuran (PBI) di Puskesmas. Menurut Zeithaml, Berry dan Parasuraman (dalam Yamit, 2017:10-11) dimensi kualitas yang dimaksud adalah reliability (keterandalan), responsiveness (cepat tanggap), assurance (jaminan), empathy (empati), dan tangible (nyata). Untuk dapat menentukan kebijakan pelayanan yang tepat, khususnya dalam pelayanan kepada pasien, diperlukan kajian tentang dimensi kualitas pelayanan kepada pasien Puskesmas.

Berdasarkan latar belakang sebagaimana dibahas sebelumnya, maka tujuan penelitian ini adalah untuk mendikripsikan persepsi mutu pelayanan dan kepuasan pasien Penerima Bantuan Iuran (PBI) di Puskesmas Pahandut Kota Palangka Raya, untuk menganalisis signifikansi pengaruh dimensi mutu pelayanan yang meliputi reliability, responsiveness, assurance, empathy, tangibles secara parsial tehadap tingkat kepuasan pasien Penerima Bantuan Iuran (PBI) di Puskesmas Pahandut Kota Palangka Raya, untuk menganalisis signifikansi pengaruh dimensi mutu pelayanan yang meliputi reliability, responsiveness, assurance, empathy, tangibles secara simultan tehadap tingkat kepuasan pasien Penerima Bantuan Iuran (PBI) di Puskesmas Pahandut Kota Palangka Raya serta untuk mengkaji manakah diantara dimensi kuliatas layanan yang berpengaruh dominan pada tingkat kepuasan pasien Penerima Bantuan Iuran (PBI).

\section{KAJIAN LITERATUR}

Menurut Zeithaml, Berry dan Parasuraman, (dalam Yamit, 2017 :10-12) telah melakukan berbagai penelitian terhadap beberapa jenis jasa, dan berhasil mengidentifikasi lima dimensi karakteristik yang digunakan oleh para pelanggan dalam mengevaluasi kualitas pelayanan. Kelima dimensi karakteristik kualitas pelayanan tersebut adalah:

a. Reliability (kehandalan), yaitu kemampuan dalam memberikan pelayanan dengan segera dan memuaskan serta sesuai dengan telah yang dijanjikan.

b. Responsiveness (daya tangkap), yaitu keinginan para staf untuk membantu para pelanggan dan memberikan pelayanan dengan tanggap. c. Assurance (jaminan), yaitu mencakup kemampuan, kesopanan dan sifat dapat dipercaya yang dimiliki para staf, bebas dari bahaya, resiko ataupun keragu-raguan.

d. Empathy, yaitu meliputi kemudahan dalam melakukan hubungan, komunikasi yang baik, dan perhatian dengan tulus terhadap kebutuhan pelanggan.

e. Tangibles (bukti langsung), yaitu meliputi fasilitas fisik, perlengkapan, pegawai, dan sarana komunikasi.

Dimensi kualitas yang dikemukakan oleh Zeithaml, Berry dan Parasuraman tersebut berpengaruh pada harapan pelanggan dan kenyataan yang mereka terima. Jika kenyataannya pelanggan menerima pelayanan melebihi harapannya, maka pelanggan akan mengatakan pelayanannya berkualitas dan jika kenyataannya pelanggan menerima pelayanan kurang atau sama dari harapannya, maka pelanggan akan mengatakan pelayanannya tidak berkualitas atau tidak memuaskan. Dimensi kualitas diatas dapat dijadikan dasar bagi pelaku bisnis untuk mengetahui apakah ada kesenjangan (gap) atau perbedaan antara harapan pelanggan dan kenyataan yang mereka terima. Harapan pelanggan sama dengan keinginan pelanggan yang ditentukan oleh informasi yang mereka terima dari mulut ke mulut, kebutuhan pribadi, pengalaman masa lalu dan komunikasi eksternal melalui iklan dan promosi. Jika kesenjangan antara harapan dan kenyataan cukup besar, hal ini menunjukkan bahwa perusahaan tidak mengetahui apa yang diinginkan oleh pelanggannya.

Kualitas jasa pelayanan sangat dipengaruhi oleh harapan konsumen. Harapan konsumen dapat bervariasi dari konsumen satu dengan konsumen lain walaupun pelayanan yang diberikan konsisten. Kualitas mungkin dapat dilihat sebagai suatu kelemahan kalau konsumen mempunyai harapan yang terlalu tinggi, walaupun dengan suatu pelayanan yang baik.

Menurut Wyckof dalam Lovelock (yang dikutip dari Purnama,2006 : 19-20) memberikan pengertian kualitas layanan sebagai tingkat kesempurnaan tersebut untuk memenuhi keinginan konsumen, sedangkan menurut Parasuraman, et al. Kaulitas layanan merupakan perbandingan antara layanan yang dirasakan ( persepsi) konsumen dengan kualitas layanan yang diharapkan konsumen. Jika kualitas layanan yang dirasakan sama atau melebihi kualitas layanan yang diharapkan, maka layanan dikatakan berkualitas dan memuaskan.

Apa sebenarnya kepuasan pasien itu? Untuk mendefinisikan kepuasan pasien sebenarnya 
tidaklah mudah, karena pasien memiliki berbagai macam karakteristik, baik pengetahuan, strata sosial, pengalaman, pendapatan maupun harapan. Misalnya, seorang pasien yang baru ingin mencoba jasa kesehatan tertentu dari sebuah Puskesmas. Sebelum pasien datang bertransaksi, pasien baru tersebut pasti memiliki harapan bahwa dia akan dilayani secara baik, pelayannya ramah, cepat tanggap, dan terapi pengobatannya baik. Jika harapan pasien ini sesuai dengan apa yang dialami dan dirasakan melebihi harapannya sudah dapat dipastikan pasien tersebut akan merasa puas.

Tetapi bila yang dialami dan dirasakan pasien tidak sesuai dengan harapannya, misal pelayanannya tidak ramah, tidak tanggap dan terapinya tidak mujarap, sudah dapat dipastikan pasien tidak merasa puas. Dari contoh diatas, kepuasan pasien dapat diketahui setelah menggunakan produk dan jasa pelayanan. Dengan kata lain kepuasan pasien merupakan evaluasi purna beli atau hasil evaluasi setelah membandingkan apa yang dirasakan dengan harapannya. Dari penjelasan tersebut dapat disimpulkan bahwa kepuasan pasien adalah hasil (outcome) yang dirasakan atas penggunaan produk jasa kesehatan, sama atau melebihi harapan (dalam Zulian Yamit, 2017:78) Kepuasan pasien telah menjadi konsep sentral dalam wacana manajemen (Tjiptono dan Chandra, 2005:192). Pasien Puskesmas umumnya mengharapkan jasa layanan kesehatan yang diterima dan dinikmatinya dengan pelayanan yang baik atau memuaskan (Assauri, 2003): Kepuasan pasien dapat membentuk persepsi dan selanjutnya dapat meningkatkan posisioning jasa layanan kesehatan Puskesmas di mata masyarakat.

\section{Mengukur Kepuasan Pasien}

Kotler (dalam Yamit, 2017:80) mengemukakan beberapa metode yang dapat digunakan untuk mengukur kepuasan pasien, metode tersebut antara lain:

a. Sistem pengaduan. Sistem ini memberikan kesempatan kepada pasien untuk memberikan saran, keluhan dan bentuk ketidak puasan lainnya dengan cara menyediakan kotak saran. Setiap saran dan keluhan yang masuk harus menjadi perhatian menejemen, sebab saran dan keluhan itu pada umumnya dilandasi oleh pengalaman mereka dan hal ini sebagai bentuk kecintaan mereka terhadap sebuah organisasi.

b. Survey pasien. Survey pasien merupakan cara yang umum digunakan dalam mengukur kepuasan pasien misalnya, melalui surat pos, telepon, atau wawancara secara langsung.

c. Panel pasien. Pihak menejemen mengundang pasien yang setia dan mengundang juga pasien yang telah pindah menjadi pasien di tempat lain. Dari pasien yang setia akan diperoleh informasi tingkat kepuasan yang mereka rasakan dan dari mantan pasien, menejemen akan memperoleh informasi mengapa hal itu dapat terjadi. Apabila pasien yang tidak setia (customer loss rate) ini meningkat hal ini menunjukkan kegagalan menejemen dalam memuaskan pasien.

Wiyono dan Wahyudin (2009) dalam penelitiannya yang menguji tentang pengaruh kualitas pelayanan medis, paramedis, dan penunjang medis terhadap kepuasan konsumen di Rumah Sakit Islam Manisrenggo Klaten. Tujuan penelitiannya adalah untuk mengetahui pengaruh kualitas pelayanan medis, paramedis, dan penunjang medis terhadap kepuasan konsumen di Rumah Sakit Islam Manisrenggo Klaten. Metode analisis data yang digunakan adalah uji validitas dan uji reliabilitas kuesioner. Hasil analisis data menunjukkan bahwa semua variabel kualitas pelayanan secara signifikan memiliki pengaruh terhadap kepuasan konsumen di Rumah Sakit Islam Manisrenggo Klaten. Variabel kualitas pelayanan medis memiliki pengaruh signifikan terhadap kepuasan konsumen dengan tingkat signifikansi 7 $\%$. Variabel kualitas pelayanan paramedis memiliki pengaruh signifikan terhadap kepuasan konsumen dengan tingkat signifikansi 8,8\%. Variabel kualitas pelayanan penunjang medis memiliki pengaruh signifikan terhadap kepuasan konsumen dengan tingkat signifikansi 8,9 Koefisien kualitas pelayanan medis 0,05427 dan bertanda positif. Artinya, jika kualitas pelayanan medis meningkat 1 skor, maka kepuasan konsumen akan meningkat 0,05427 skor. Koefisien kualitas pelayanan paramedis sebesar 0,06994 dan juga bertanda positif. Hal ini berarti kenaikan 1 skor kualitas pelayanan paramedis akan mengakibatkan kenaikan 0,06994 skor pada kepuasan konsumen. Koefisien kualitas pelayanan penunjang medis sebesar 0,06287 (juga bertanda positif), berarti kenaikan 1 skor variabel ini akan mengakibatkan kenaikan 0,06287 skor kepuasan konsumen. Hasil analisis data dan pembahasan tersebut menunjukkan bahwa pada tingkat signifikansi $10 \%$ ketiga hipotesis alternatif yang diajukan dalam penelitian ini dapat diterima.

\section{Kerangka Konseptual}

Sebelum melakukan perumusan hipotesis penelitian maka digambarkan terlebih dahulu sebuah kerangka konsep penelitian. Kerangka konseptual pada kegiatan penelitian ilmiah ini adalah bahwa mutu pelayanan kesehatan pasien Penerima Bantuan Iuran (PBI) merupakan suatu yang cukup penting pada kepuasan pasien, baik 
bagi pasien itu sendiri maupun bagi menejemen puskesmas. Dengan mutu pelayanan yang lebih baik, maka kemungkinan besar dapat memuaskan pasien Penerima Bantuan Iuran (PBI) sekaligus dapat mewujudkan visi dan misi operasional Puskesmas. Berdasarkan logika teoritis, pada kegiatan penelitian ini mutu pelayanan dikaitkan dengan kepuasan pasien Penerima Bantuan Iuran (PBI), maka kerangka konseptual dapat dilihat pada gambar 3.1, tentang kerangka konseptual penelitian, sebagai berikut :

Gambar 1. Bagan Kerangka Konseptual Penelitian

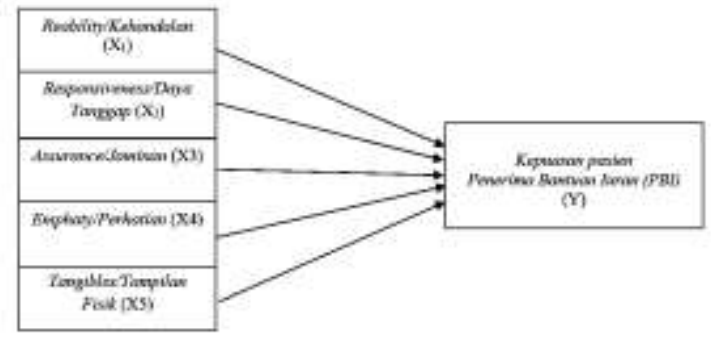

Hipotesis

Hipotesis adalah suatu perumusan sementara mengenai suatu hal yang dibuat untuk menjelaskan hal itu dan juga dapat menuntun dan mengarahkan penyelidikan selanjutnya (Husein, 2003) Hipotesis penelitian tersebut masih harus dibuktikan kebenarannya secara empiris melalui kegiatan penelitian ilmiah. Dengan kata lain, hipotesis merupakan dugaan yang masih dimungkinkan benar atau salah.

Berdasarkan rumusan permasalahan, tujuan penelitian, tinjaun pusatak dan kerangka konseptual yang telah diuraikan, maka pernyataan hipotesis yang dirumuskan pada kegiatan penelitian ini sebagai berikut:

- Diduga secara parsial, mutu pelayanan yang terdiri dari reliability, responsiveness, assurance, empathy dan tangibles berpengaruh signifikan terhadap kepuasan pasien Penerima Bantuan Iuran (PBI).

- Diduga secara simultan, mutu Pelayanan yang terdiri dari reliability, responsiveness, assurance, empathy dan tangibles berpengaruh signifikan terhadap kepuasan pasien Penerima Bantuan Iuran (PBI)

- Diduga dimensi Pelayanan responsiveness berpengaruh dominan terhadap kepuasan pasien Penerima Bantuan Iuran (PBI)

\section{Model Analisis}

Pada kegiatan penelitian ilmiah ini menggunakan model analisis regresi linier berganda (Multiple Regression Analysis). Model ini dipilih karena penulis ingin mengetahui seberapa besar pengaruh dimensi mutu pelayanan yang meliputi reliability, responsiveness, assurance, empathy, tangibles tehadap tingkat kepuasan pasien Penerima Bantuan Iuran (PBI), baik secara simultan maupun secara parsial.

Dengan menggunakan teknik analisis regresi linier berganda, maka besarnya pengaruh dimensi mutu Pelayanan yang meliputi reliability, responsiveness, assurance, empathy, tangibles dengan tingkat kepuasan pasien Penerima Bantuan Iuran (PBI) di Puskesmas akan dapat diketahui. Hal itu akan terlihat pada besarnya koefisien dari masing-masing dimensi Pelayanan. Pengujian hipotesis ini dilakukan dengan menggunakan uji statistik, baik uji t maupun uji F.

\section{METODE PENELITIAN}

Untuk melaksanakan kegaiatan penelitian tentang Analisis Pengaruh Tingkat Kualitas Pelayanan Kesehatan Terhadap Kepuasan Pasien Penerima Bantuan Iuran (PBI) di Puskesmas Pahandut Kota Palangka Raya ini maka akan diawali dengan mendiskripsikan rancangan penelitian. Rancangan kegiatan penelitian empirik ini menggunakan pendekatan kuantitatif, yang dimaksudkan untuk menganalisis pengaruh antara variabel Pelayanan dan kepuasan pasien Penerima Bantuan Iuran (PBI) di puskesmas Pahandut. Berdasarkan tujuan penelitian yang telah dirumuskan sebelumnya dan apabila dilihat dari sifat hubungan antar variabel termasuk penelitian exsplanatif (exsplanatory) yaitu penelitian yang dimaksudkan menjelaskan kedudukan variabelvariabel yang diteliti serta pengaruh antara satu variabel dengan variabel lain (Sugiono, 2005). Teknik pengumpulan data yang digunakan dalam penelitian ini adalah survey, yaitu datang langsung ke lokasi penelitian dan mengambil sampel dari satu populasi yang menggunakan kuesioner sebagai alat pengumpul data. Sedangkan untuk memperoleh informasi dan fakta secara faktual atau eksplorasi fenomena, dan pada umumnya unit analisisnya adalah individu (Sanusi, 2009).

Pengambilan sampel untuk pasien Penerima Bantuan Iuran (PBI) yang mendapatkan pelayanan kesehatan di Puskesmas Pahandut Kota Palangka Raya menggunakan tehnik accecindental random sampling yaitu tehnik pengambilan sampel secara bebas, dimana peneliti dapat mengambil orang yang ditemui sebagai sampel penelitian, dengan catatan orang tersebut memenuhi kriteria sampel penelitian. Mengingat besarnya anggota populasi maka akan ditentukan sampel sebanyak 50 responden (Sanusi, 2009:65). Sampel yang diambil dalam penelitian ini adalah pasien yang memiliki 
kartu peserta Penerima Bantuan Iuran (PBI) serta pasien yang melakukan kunjungan ke Puskesmas Pahandut Kota Palangka Raya atas dasar inklusi yaitu tidak menderita penyakit gangguan kejiwaan atau dalam perawatan intensif, pasien dalam keadaan sadar dan dapat diajak berkomunikasi serta pasien menjalani rawat jalan di Puskesmas Pahandut Kota Palangka Raya minimal 3 kali kunjungan. Dalam menganalisis data penelitian ini digunakan metode deskriptif untuk menjawab perumusan masalah mengenai pengaruh dimensi mutu Pelayanan yang meliputi reliability, responsiveness, assurance, empathy, tangibles dengan tingkat kepuasan pasien Penerima Bantuan Iuran (PBI) di Puskesmas Pahandut Kota Palangka Raya. Karena itu untuk memperoleh data seakurat mungkin dari subyek penelitian sehingga data-data tersebut dapat dipertanggung jawabkan sangat perlu dilakukan uji validitas dan realibilitas Pada penelitian ini, teknik analisis data yang digunakan adalah analisis regresi linier berganda. Pengolahan data statistik dilakukan dengan menggunakan bantuan perangkat komputer dan software SPSS versi 23 for windows. Persamaan regresi yang diperoleh dalam suatu proses penghitungan tidak selalu baik untuk mengestimasi nilai variabel independen. Untuk rnengetahui apakah suatu persamaan regresi yang dihasilkan baik untuk mengestimasi nilai variabel dependen diperlukan pengetahuan tentang hal-hal berikut ini : Koefisien regresi (uji parsial), persentase pengaruh semua variabel independen secara bersama-sama (simultan) terhadap nilai variabel dependen serta pengaruh semua variabel independen di dalam model terhadap nilai variabel dependen (uji simultan). Pengetahuan tentang koefsien regresi bertujuan untuk memastikan apakah variabel independen yang terdapat dalam persamaan tersebut secara individu berpengaruh terhadap nilai variabel dependen (uji parsial). Caranya adalah dengan melakukan pengujian terhadap koefisien regresi setiap variabel independen.

\section{HASIL PENELITIAN DAN PEMBAHASAN}

Sebagaimana sudah dijelaskan pada teknik analisis penelitian, data-data penelitian tentang pengaruh reliability, responsiveness, assurance, empathy dan tangible terhadap kepuasan pasien Penerima Bantuan Iuran (PBI) di Puskesmas Pahandut Kota Palangka Raya akan analisis dengan model regresi linear berganda untuk mengetahui dan menganalisis. Besarnya pengaruh masingmasing variable penelitian tersebut dapat dilihat pada rekapitulasi hasil pengujian regresi pada tabel di bawah.

Tabel 2. Rekapitulasi Hasil Pengujian Regresi

\begin{tabular}{|c|c|c|c|c|c|c|}
\hline \multirow{2}{*}{ Madel } & \multicolumn{2}{|c|}{$\begin{array}{l}\text { Urestandadined } \\
\text { Cuefkiemis }\end{array}$} & \multirow{2}{*}{$\begin{array}{c}\text { Semadanditized } \\
\text { Cocfiecients } \\
\text { Besa }\end{array}$} & \multirow{2}{*}{ thinut } & \multirow{2}{*}{ T. Tated } & \multirow[b]{2}{*}{ Sig } \\
\hline & B & $\begin{array}{l}\text { Standard } \\
\text { Enece }\end{array}$ & & & & \\
\hline Costani & 15.245 & 124 & & 9.245 & 1.645 & \\
\hline Xi & 2.052 & 265 & 310. & 2.334 & & .004 \\
\hline$x_{2}$ & 1,004 & 419 & 332 & 2500 & & 015 \\
\hline$x_{3}$ & 1.039 & 404 & 251 & 2,875 & & oll \\
\hline$x 4$ & .714 & 312 & .183 & 2.345 & & 0000 \\
\hline $\mathrm{X} 5$ & 1.029 & 2000 & 253 & 3359 & & 002 \\
\hline & & & & 0.675 \\
\hline & & Kuve Dalerminas ( $\left.R^{3}\right)$ & & & & 0.456 \\
\hline \multicolumn{3}{|c|}{ Fest } & & & & 10.004 \\
\hline \multicolumn{3}{|l|}{ Fabel } & & & & 2,400 \\
\hline Probutivitas & & & & & & 0.004 \\
\hline
\end{tabular}

Sumber: Hasil Pengolahan Data Primer, SPSS. 23

Mewujudkan kepuasan pasien merupakan misi utama pada penyelenggaraan pelayanan kesehatan di puskesmas. Sehingga dalam rangka mewujudkan misi tersebut, maka penulis menganalisis dan melakukan kajian mutu Pelayanan dan pengaruhnya terhadap tingkat kepuasan pasien Penerima Bantuan Iuran (PBI) di Puskesmas Pahandut Kota Palangka Raya. Sedangkan teknik analisis data dengan menggunakan program SPSS (Statistical Program Social Sciense) Versi 23 for Windows diperoleh hasil sebagai berikut :

Rumusan hipotesis yang menyatakan, secara simultan semua dimensi Pelayanan yang meliputi Reliability (X1), Responsiveness (X2), Assurance (X3), Empathy (X4) dan Tangible (X5) berpengaruh terhadap kepuasan pasien Penerima Bantuan Iuran (PBI) (Y), dengan hasil uji $\mathrm{F}$ hitung $=10.004>\mathrm{F}$ tabel $=2,400$. Maknanya, pasien Penerima Bantuan Iuran (PBI) di Puskesmas Pahandut Kota Palangka Raya dalam menilai dimensi Pelayanan berpengaruh positif terhadap kepuasannya. Realitas ini tentu mendukung kinerja institusional secara menyeluruh guna mendorong terwujudnya misi penyelenggaraan puskesma secara optimal.

Hasil penelitian ini linear dengan ungkapan Wiyono dan Wahyudin (2005) dalam hasil risetnya tentang pengaruh kualitas Pelayanan medis, paramedis, dan penunjang medis terhadap kepuasan konsumen di Rumah Sakit Islam Manisrenggo Klaten. Tujuan penelitiannya adalah untuk menganalisis pengaruh kualitas Pelayanan medis, paramedis, dan penunjang medis terhadap kepuasan pasien di Rumah Sakit Islam Manisrenggo Klaten. Berdasarkan hasil analisis data terungkap bahwa semua variabel kualitas Pelayanan secara signifikan memiliki pengaruh terhadap kepuasan konsumen di Rumah Sakit Islam Manisrenggo Klaten. Yang menarik, temuan tesebut juga didukung oleh Gilmoore (2010:15), bahwa semua dimensi Pelayanan memang sebagai suatu kondisi yang dapat memberikan kepuasan publik apapun lembaganya, baik lembaga bisnis 
maupun lembaga-lembaga pelayanan publik milik pemerintah.

Rumusan hipotesis yang menduga bahwa secara parsial masing-masing varibel dimensi Pelayanan medis mempunyai pengaruh terhadap kepuasan pasien Penerima Bantuan Iuran (PBI) pada puskesmas cukup terbukti kebenarannya. Hal ini karena berdasarkan hasil uji t untuk masingmasing variabel mempunyai pengaruh signifikan terhadap kepuasan pasien Penerima Bantuan Iuran (PBI) Puskesmas Kota Palangka Raya. Hasil Uji t dapat ditunjukkan sebagai berikut :

Dimensi reliability $(\mathrm{X} 1)$, $\mathrm{t}$-hitung $=2.334>\mathrm{t}$ tabel $=1.645$. Hasil perhitungan ini tentang pengujian $\mathrm{t}$ dengan menggunakan program SPSS 19 fo Windows diketahui bahwa dimensi reliability mempunyai pengaruh signifikan terhadap terhadap tingkat kepuasan pasien Penerima Bantuan Iuran (PBI) di Puskesmas Pahandut Kota Palangka Raya. Hasil riset ini sependapat dengan hasil temuan penelitian Sulistyowati (2010) yang menyatakan reliability mempunyai pengaruh signifikan terhadap Pelayanan pada di IndoSpring, Tbk Surabaya. Temuan ini menunjukkan bahwa pasien Penerima Bantuan Iuran (PBI) pada puskesmas tersebut sudah memberikan persepsi tentang reliability yang dapat meningkatkan kepuasan sudah baik untuk mendukung kinerja institusional, bahwa reliability merupakan sebuah media kebutuhan dalam diri pasien yang perlu dipenuhi agar pasien tersebut dapat merasakan kepuasan Pelayanan kesehatan.

Varibel responsiveness (X3): t-hitung = 2.500> $\mathrm{t}$ tabel $=1.645$. Hasil perhitungan ini tentang pengujian $\mathrm{t}$ dengan menggunakan program SPSS 17 diketahui bahwa variabel responsiveness mempunyai pengaruh signifikan terhadap terhadap tingkat kepuasan pasien Penerima Bantuan Iuran (PBI) di Puskesmas Pahandut Kota Palangka Raya. Hasil riset ini sependapat dengan hasil temuan penelitian Sulistyowati (2010) yang menyatakan reliability mempunyai pengaruh signifikan terhadap Pelayanan pada di IndoSpring, Tbk Surabaya. Temuan ini menunjukkan bahwa pasien Penerima Bantuan Iuran (PBI) pada puskesmas tersebut sudah memberikan persepsi tentang reliability yang dapat meningkatkan kepuasan sudah baik untuk mendukung kinerja institusional, bahwa reliability merupakan sebuah media kebutuhan dalam diri pasien yang perlu dipenuhi agar pasien tersebut dapat merasakan kepuasan Pelayanan kesehatan. Hal tersebut senada juga diungkapkan Isdaryati (2009: 15) yang menyatakan bahwa responsiveness mempengaruhi tingakt pelayanan publik. Pendapat lain yang mendukung temuan dari penelitian ini adalah dari Kottler (2009) dalam Arifin (2007: 175) yang mengemukakan bahwa responsiveness merupakan dimensi Pelayanan yang sangat mempengaruhi terhadap Pelayanan bisnis jasa termasuk sektor binis kesehatan.

Varibel assurance (X3): t-hitung $=2.675>\mathrm{t}$ tabel $=1.645$. Hasil perhitungan ini tentang pengujian $\mathrm{t}$ dengan menggunakan program SPSS 19 diketahui bahwa variabel assurance mempunyai pengaruh signifikan terhadap terhadap tingkat kepuasan pasien Penerima Bantuan Iuran (PBI) di Puskesmas Pahandut Kota Palangka Raya. Hasil riset ini sependapat dengan hasil temuan penelitian Sulistyowati (2010) yang menyatakan reliability mempunyai pengaruh signifikan terhadap Pelayanan pada di IndoSpring, Tbk Surabaya. Temuan ini menunjukkan bahwa pasien Penerima Bantuan Iuran (PBI) pada puskesmas tersebut sudah memberikan persepsi tentang reliability yang dapat meningkatkan kepuasan sudah baik untuk mendukung kinerja institusional, bahwa reliability merupakan sebuah media kebutuhan dalam diri pasien yang perlu dipenuhi agar pasien tersebut dapat merasakan kepuasan Pelayanan kesehatan. Hal tersebut senada juga diungkapkan Isdaryati (2009: 15) yang menyatakan bahwa responsiveness mempengaruhi tingakt pelayanan publik. Pendapat lain yang mendukung temuan dari penelitian ini adalah dari Kottler (2009) dalam Arifin (2007: 175) yang mengemukakan bahwa responsiveness merupakan dimensi Pelayanan yang sangat mempengaruhi terhadap Pelayanan bisnis jasa termasuk sektor binis kesehatan.

Varibel emphaty (X4): $\mathrm{t}-$ hitung $=2.345>\mathrm{t}$ tabel $=1.645$. Hasil perhitungan ini tentang pengujian $t$ dengan menggunakan program SPSS 19 diketahui bahwa variabel emphaty mempunyai pengaruh signifikan terhadap terhadap tingkat kepuasan pasien Penerima Bantuan Iuran (PBI) di Puskesmas Pahandut Kota Palangka Raya. Hasil riset ini sependapat dengan hasil temuan penelitian Sulistyowati (2010) yang menyatakan reliability mempunyai pengaruh signifikan terhadap Pelayanan pada di IndoSpring, Tbk Surabaya. Temuan ini menunjukkan bahwa pasien Penerima Bantuan Iuran (PBI) pada puskesmas tersebut sudah memberikan persepsi tentang reliability yang dapat meningkatkan kepuasan sudah baik untuk mendukung kinerja institusional, bahwa reliability merupakan sebuah media kebutuhan dalam diri pasien yang perlu dipenuhi agar pasien tersebut dapat merasakan kepuasan Pelayanan kesehatan. Hal tersebut senada juga diungkapkan Isdaryati (2009: 15) yang menyatakan bahwa responsiveness 
mempengaruhi tingakt pelayanan publik. Pendapat lain yang mendukung temuan dari penelitian ini adalah dari Kottler (2009) dalam Arifin (2007: 175) yang mengemukakan bahwa responsiveness merupakan dimensi Pelayanan yang sangat mempengaruhi terhadap Pelayanan bisnis jasa termasuk sektor binis kesehatan.

Varibel tangible (X5): t-hitung $=3.359>\mathrm{t}$ tabel $=1.645$. Hasil perhitungan ini tentang pengujian $\mathrm{t}$ dengan menggunakan program SPSS 19 diketahui bahwa variabel assurance mempunyai pengaruh signifikan terhadap terhadap tingkat kepuasan pasien Penerima Bantuan Iuran (PBI) di Puskesmas Pahandut Kota Palangka Raya. Hasil riset ini sependapat dengan hasil temuan penelitian Sulistyowati (2010) yang menyatakan reliability mempunyai pengaruh signifikan terhadap Pelayanan pada di IndoSpring, Tbk Surabaya. Temuan ini menunjukkan bahwa pasien Penerima Bantuan Iuran (PBI) pada puskesmas tersebut sudah memberikan persepsi tentang reliability yang dapat meningkatkan kepuasan sudah baik untuk mendukung kinerja institusional, bahwa reliability merupakan sebuah media kebutuhan dalam diri pasien yang perlu dipenuhi agar pasien tersebut dapat merasakan kepuasan Pelayanan kesehatan. Hal tersebut senada juga diungkapkan Isdaryati (2009: 15) yang menyatakan bahwa responsiveness mempengaruhi tingakt pelayanan publik. Pendapat lain yang mendukung temuan dari penelitian ini adalah dari Kottler (2009) dalam Arifin (2007: 175) yang mengemukakan bahwa responsiveness merupakan dimensi Pelayanan yang sangat mempengaruhi terhadap Pelayanan bisnis jasa termasuk sektor binis kesehatan.

Dengan kata lain, dimensi Pelayanan yang memberikan pengaruh lebih dominan terhadap kepuasan pasien Penerima Bantuan Iuran (PBI) pada Puskesmas Pahandut Kota Palangka Raya adalah responsiveness. Sehingga sebagai kepala puskesmas mempunyai tugas untuk menggerakkan segala sumber yang ada di lembaganya sehingga dapat didayagunakan secara maksimal untuk mencapai tujuan yang telah ditetapkan. Baik tidaknya kualitas Pelayanan kesehatan di puskesmas sangat bergantung pada bagaimana kemampuan kepala menejemen dalam memotivasi perilaku karyawannya dalam melaksanakan tugasnya, sebab menurut Hendrawan (2009: 225) dalam melaksanakan tugasnya karyawan cenderung tunduk pada pimpinan sehingga segala sesuatu yang dilaksanakan oleh karyawan harus mengacu pada kebijakan-kebijakan dari menejemen. Selain itu apabila terjadi penyimpangan-penyimpangan dalam pelaksanaan kebijakan tersebut, menejemen puskesmas berhak untuk menegur maupun memberikan peringatan.

\section{PENUTUP}

Berdasarkan analisis gap dimensi Pelayanan secara keseluruhan, kesesuaian antara Pelayanan yang diberikan oleh Puskesmas Pahandut Kota Palangka Raya dengan harapan pasien Penerima Bantuan Iuran (PBI) terdapat gap/ tingkat kepuasan sebesar (- 10.54 ), skor ini dikategorikan dalam kelompok sedang, meskipun belum sepenuhnya memenuhi harapan pasien Penerima Bantuan Iuran (PBI), tetapi Pelayanan yang diberikan sudah cukup baik. Berdasarkan hasil analisis regresi diatas dapat disimpulkan bahwa semua variabel dari dimensi kualitas Pelayanan (Reliability, Responsiveness, Assurance, Empathy, Tangible) secara bersama-sama memiliki pengaruh positif dan signifikan terhadap kepuasan pasien Penerima Bantuan Iuran (PBI) Puskesmas Pahandut Kota Palangka Raya. Hasil tersebut menunjukkan bahwa hipotesis alternatif (Ha) dapat diterima dan hipotesis nihil (Ho) ditolak. Sedangkan besar pengaruhnya adalah variabel Assurance (1.052), Reliability (1.004), Tangible (1.039), Responsiveness (1.714), Empathy (1.029) terhadap kepuasan pasien Penerima Bantuan Iuran (PBI). Selanjutnya nilai adalah $\mathrm{R}^{2}$ sebesar (0.456) menunjukkan bahwa 45,6\% variabel kepuasan pasien dapat dijelaskan oleh service quality yaitu Reliability, Responsiveness, Assurance, Empathy, dan Tangible sedangkan sisanya 54,4\% lainnya dijelaskan variabel lain yang tidak termasuk dalam model penelitian ini. Berdasarkan hasil analisis gap (kesesuaian antara harapan dengan kinerja) tiap dimensi, adalah sebagai berikut, variabel Responsiveness ( -0.78) skor ini dikategorikan sedang. kemudian variabel selanjutnya diikuti variabel Tangible (-0.88), variabel Reliability ($0.57)$, variabel assurance (-0.11), dan yang terakhir variabel Empathy (-0.11). Meskipun belum sepenuhnya Pelayanan yang diberikan sesuai harapan tetapi Pelayanan Puskesmas Pahandut Kota Palangka Raya sudah cukup baik namun harus terus ditingkatkan.

Manejemen Puskesmas Pahandut Kota Palangka Raya nampaknya perlu secara berkala mengamati aktivitas Pelayanan pada pasien agar dapat mempertahankan kelebihan-kelebihan yang ada dan selalu meningkatkan kualitas Pelayanan pada variabel-variabel yang masih kurang penilaiannya atau menurut penilaian pasien belum sesuai dengan yang diharapakan oleh pasien, hal ini bisa dilakukan dengan lebih memperhatikan 
terhadap kebutuhan dan keinginan pasien, peningkatan fasilitas sarana dan prasarana, jaminan rasa aman, nyaman, dan kepercayaan serta Pelayanan yang dijanjikan secara cepat, akurat dan pasti sehingga akan meningkatkan kepuasan pasien. Secara empiric, semua dimensi kualitas Pelayanan termyata mempunyai pengaruh positif dan signifikan terhadap kepuasan pasien Penerima Bantuan Iuran (PBI), sehingga menejemen Puskesmas Pahandut Kota Palangka Raya perlu memperhatikannya berdasarkan peringkat prioritas dan bila perlu melakukan berbagai inovasi lain yang dapat meningkatkan kepuasan pasien Penerima Bantuan Iuran (PBI).

\section{DAFTAR PUSTAKA}

Anastasi, Ferika (2007), Strategi Menyusun Instrumen Penelitian, Cetakan Pertama, Penerbit Pustaka Media, Bandung.

Dinas Kesehatan Kota Palangka Raya, Profil Kesehatan Kota Palangka Raya Tahun 2019, Palangka Raya, Dinkes Kota Palangka Raya, 2020

Gaspersz, Vincent. (2007). Manajemen Kualitas dalam Industri Jasa. Gramedia :Jakarta.

Garvin, David. (2008), Service Managemet in Public Sevice, The Fifth Edition, Prentice Hall, Washington.

Gay, Mathew \& Diehl, Goerge, (1992), Test of Validity and Reliability, The Boston University Press, Boston

Guntur, Setiyadi dan Setiaji, Norachmad, (2009), Pengaruh kualitas Pelayanan dengan lima dimensi kualiats (Tangibles, Reliability Responsiveness, Assurance, Empathy) terhadap kepuasan pelanggan di PDAM kota Surakarta, tesis tidak dipublikasi.

Kementerian Kesehatan RI, Pedoman Pelaksanaan Jaminan Kesehatan Masyarakat (PENERIMA BANTUAN IURAN (PBI)), Jakarta, Kementerian Kesehatan RI, 2019

Kotler, Philip. (2005). Marketing Management. (Edisi Indonesia oleh Hendra Teguh, Ronny dan Benjamin Molan). PT Indeks: Jakarta.

Long Convey \& Chwalek, (2006), Research Methodology, California Publisher \& Sons, California.

Nawawi, (2005), Metode Penelitaan Praktis, Edisi
Kedua, Cetakan Keempat, Penerbit Bulan Bintang, Bandung.

Purnama, Nursyahbani. (2006). Manajemen Kualitas Perspektif Global. Edisi Pertama, Cetakan Pertama. Penerbit Ekonisia Kampus Fakultas Ekonomi UII Yogyakarta.

Siregar, Rismahani, (2018) Pengaruh Persepsi Peserta BPJS Penerima Bantuan Iuran (PBI) Tentang Mutu Pelayanan Terhadap Kepuasan Pasien di Puskesmas Medan Labuhan Tahun 2018, http://repositori.usu.ac.id/handle/12345678 9/11341, Universitas Sumatra Utara, Medan

Sanusi, Anwar, (2009), Metode Penelitian Untuk Ekonomi dan Bisnis, Penerbit Salemba Empat, Cetakan Petama, Jakarta.

Solimun, Akhmad, (2004), Kiat-Kiat Melakukan Penelitian Ilmiah, Cetakan Kedua, Edisi Kedua, Penerbit Bayumedia, Malang.

Stanton, William. J. (2009). Fundamentals of Marketing. (Edisi Indonesia oleh Sadu Sundani). Erlangga.: Jakarta.

Sugiono, (2005), Metode Penelitian Untuk IlmuIlmu Sosial, Cetakan Kelima, Penerbit Andi Offset, Yogyakarta.

Suhartono, (2007), Selayang Pandang Penelitian Ilmiah, Cetakan Pertama, Penebit Diomamedia, Malang.

Tjiptono, Fandi dan Gregorius Candra .(2005). Service, Quality, and Satisfaction. Andi Offset: Yogyakarta.

Wiyono, Eddy dan Wahyudin, Achmad, (2009), Pengaruh kualitas Pelayanan medis, paramedis, dan penunjang medis terhadap kepuasan konsumen di Rumah Sakit Islam Manisrenggo Klaten, Tesis tidak dipublikasi

Yamit, Zulian. (2017) .Manajemen Produksi dan Operasi. Edisi Pertama, Penerbit Ekonisia Kampus Fakultas Ekonomi UII Yogyakarta. Dokumentasi Puskesmas Pahandut, Kota Palangka Raya, 2019.

\section{Profil Penulis :}

1. Rolly Adinovi, Pendidikan Ekonomi, FKIP, Universitas Palangakaraya

2. Dr. Rinto Alexandro, Pendidikan Ekonomi, FKIP, Universitas Palangakaraya Email : rinto.alexandro@fkip.upr.ac.id 